\title{
Síndrome de desmielinização osmótica: relato de caso com evolução favorável*
}

\author{
Osmotic demyelination syndrome: report of a case with favorable outcome \\ Mauro Eduardo Jurno ${ }^{1}$, Marina Horta Azevedo de Castro ${ }^{2}$, Mariana de Assis Lage ${ }^{2}$, João Henrique \\ Dupin $^{3}$, Antonio José Fonseca de Paula ${ }^{4}$, Gustavo de Vasconcelos Bello ${ }^{5}$
}

\begin{abstract}
Resumo Os autores relatam um caso de paciente apresentando evolução favorável após confirmado diagnóstico de síndrome de desmielinização osmótica (mielinólise pontina central e extrapontina) através de exame de ressonância magnética. Unitermos: Síndrome de desmielinização osmótica; Mielinólise osmótica; Mielinólise pontina e extrapontina.
\end{abstract}

Abstract The authors report a case of a patient with favorable outcome after diagnosis of osmotic demyelination syndrome (central pontine and extrapontine myelinolysis) confirmed by magnetic resonance imaging.

Keywords: Osmotic demyelination syndrome; Osmotic myelinolysis; Central pontine and extrapontine myelinolysis.

Jurno ME, Castro MHA, Lage MA, Dupin JH, Paula AJF, Bello GV. Síndrome de desmielinização osmótica: relato de caso com evolução favorável. Radiol Bras. 2012 Jan/Fev;45(1):61-62.

\section{INTRODUÇÃO}

Neste artigo relata-se um caso de uma paciente apresentando evolução favorável de síndrome de desmielinização osmótica, confirmada por exame de ressonância magnética (RM).

\section{RELATO DO CASO}

Paciente do sexo feminino, 60 anos de idade, leucoderma, procurou atendimento médico em razão de quadro de pirose, náuseas e vômitos. Passado de transtorno depressivo maior, em tratamento domiciliar com risperidona e nortriptilina. Segundo familiares, a notícia da gravidez da filha foi o evento estressante que desencadeou o quadro atual. Durante a internação, os neu-

* Trabalho realizado no Hospital Regional de Barbacena FHEMIG, Barbacena, MG, Brasil.

1. Doutor, Coordenador da Residência de Clínica Médica do Hospital Regional de Barbacena - FHEMIG, Professor da Faculdade de Medicina de Barbacena, Barbacena, MG, Brasil.

2. Médicos Residentes de Clínica Médica do Hospital Regional de Barbacena - FHEMIG, Barbacena, MG, Brasil.

3. Médico Residente de Psiquiatria de Centro Hospitalar Psiquiátrico de Barbacena - FHEMIG, Barbacena, MG, Brasil.

4. Médico Clínico Geral e Oncologista, Preceptor de Clínica Médica do Hospital Regional de Barbacena - FHEMIG, Barbacena, MG, Brasil.

5. Médico Radiologista, Membro Titular do Colégio Brasileiro de Radiologia e Diagnóstico por Imagem (CBR), Barbacena, MG, Brasil.

Endereço para correspondência: Dr. Mauro Eduardo Jurno. Rua Fernando Laguardia, 45, Santa Tereza II (Geraldo Xavier). Barbacena, MG, Brasil, 36201-118. E-mail: jurno@uol.com.br

Recebido para publicação em 17/1/2011. Aceito, após revisão, em 25/7/2011. rolépticos em uso foram suspensos. Análise laboratorial revelou distúrbio hidroeletrolítico importante: hiponatremia (sódio: $123 \mathrm{mEq} / \mathrm{l}$; VR: 135 a $145 \mathrm{mEq} / \mathrm{l}$ ) e hipopotassemia (potássio: 2,6 mEq/l; VR: 3,5 a 5,2 mEq/l). Foi iniciada reposição iônica, sendo constatada natremia de $147 \mathrm{mEq} / 1$ nas primeiras 48 horas após a admissão.

A paciente iniciou com adinamia e prostração. Após avaliação psiquiátrica, foram administrados clonazepam e mirtazapina, porém houve piora do quadro clínico. A paciente apresentou prostração importante, sonolência, hiporresponsividade, abertura ocular somente aos estímulos, resposta motora inespecífica (reflexo de retirada), resposta verbal incompreensível (escala de coma de Glasgow: 9), sendo transferida ao centro de terapia intensiva. Avaliação física à admissão nesta unidade evidenciou pupilas isocóricas e fotorreagentes, sem rigidez de nuca. Babinski à direita e paresia em membro superior direito. A paciente evoluiu com quadro de tetraparesia espástica e mutismo.

Exame de tomografia computadorizada de encéfalo não mostrou alterações. Diante da persistência do quadro de rebaixamento do nível de consciência, mesmo após normalizados os níveis séricos de sódio e potássio da paciente, foi feito exame de RM, que revelou hiperintensidade de sinal em $\mathrm{T} 2$, comprometendo a ponte, poupando tratos corticoespinhais, e de maneira discreta os núcleos da base e porção lateral dos tálamos, com áreas de necrose nos globos pálidos, bilateralmente (Figuras 1, 2 e 3). Não houve impregnação anômala pelo meio de contraste e o radiologista concluiu que as imagens confirmaram sinais de desmielinização osmótica, necrose dos globos pálidos e sinais de redução volumétrica infra e supratentorial.

A paciente evoluiu com melhora da deglutição, tornando possível a progressão de dieta entérica para oral. Houve também melhora da espasticidade em membros, com boa resposta com a introdução de relaxante muscular. Após um mês, com melhora progressiva do quadro clínico, a paciente voltou a contatar verbalmente (sem conseguir elevar a voz, mantendo disartria). Foi repetido exame de RM, observando-se o mesmo padrão do exame prévio. A paciente apresentou recuperação dos déficits apresentados em dois meses.

\section{DISCUSSÃO}

A síndrome de desmielinização osmótica é uma doença desmielinizante do encéfalo que atinge principalmente a região da ponte, podendo comprometer regiões extrapontinas $^{(\mathbf{1})}$. Apesar da importância de sua associação com distúrbios metabólicos, particularmente a correção rápida de hiponatremia, essa entidade pode ocorrer em pacientes sem evidência de desequilíbrio 


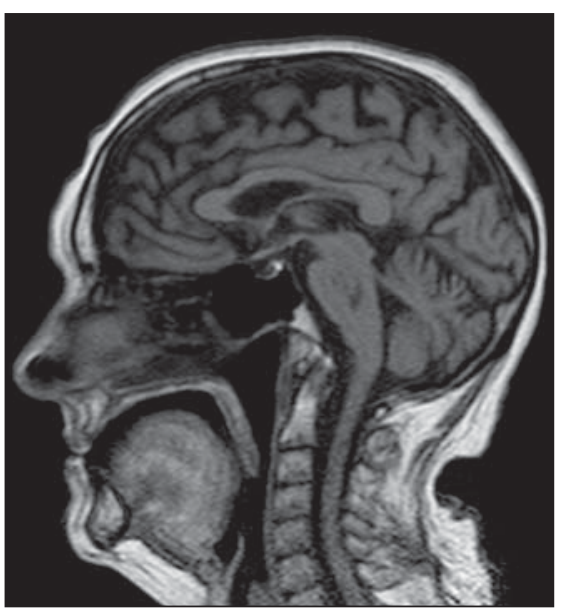

Figura 1. Ressonância magnética, corte sagital: imagem na ponte.

hidroeletrolítico ${ }^{(2)}$. Nesses casos, os pacientes geralmente apresentam outros fatores de risco, como antecedentes de abuso de álcool ou drogas, desnutrição, doença hepática, câncer e doença de Addison ${ }^{(3,4)}$. Os primeiros sintomas são geralmente o mutismo e a disartria. Alterações como letargia e mudanças afetivas são também comuns e podem ser confundidas com transtornos psiquiátricos. A evolução desses pacientes é variável, desde a recuperação total até o óbito. Em geral, a recuperação é lenta e gradativa. A mortalidade associada a hiponatremia grave situa-se entre $40 \%$ e $50 \%^{(5,6)}$

No caso aqui descrito, a hiponatremia pode ter decorrido do uso de antidepressivos ou do quadro prévio de vômitos. Torna-se importante a prevenção da síndrome de desmielinização osmótica através da

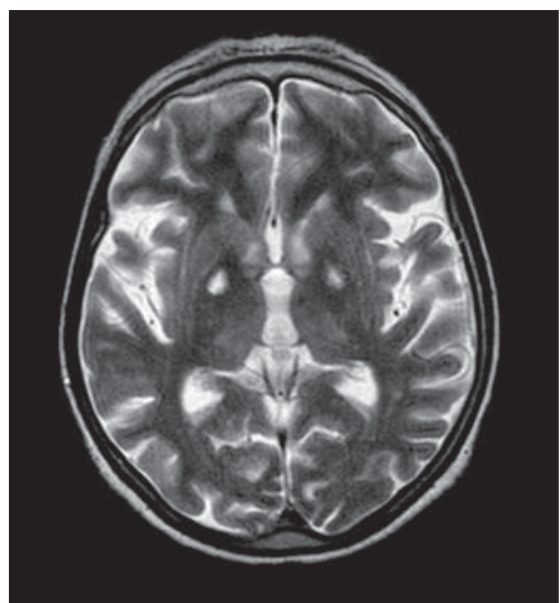

Figura 2. Ressonância magnética, corte axial: lesões extrapontinas.

conduta adequada frente a pacientes hiponatrêmicos. Alguns autores consideram impossível estabelecer um nível de correção de sódio completamente livre de risco, entretanto, em casos de hiponatremia sintomática, a reposição de sódio não deve ultrapassar 10-12 mEq em 24 horas.

O laudo da RM refere que os achados são condizentes com a síndrome de desmielinização osmótica ${ }^{(7,8)}$.

\section{REFERÊNCIAS}

1. Grafton ST, Bahls FH, Bell KR. Acquired focal dystonia following recovery from central pontine myelinolysis. J Neurol Neurosurg Psychiatry. 1988;51:1354-5

2. Pietrini V, Mozzani F, Crafa P, et al. Central pontine and extrapontine myelinolysis despite careful correction of hyponatremia: clinical and neuropathological findings of a case. Neurol Sci. 2010; 31:227-30.

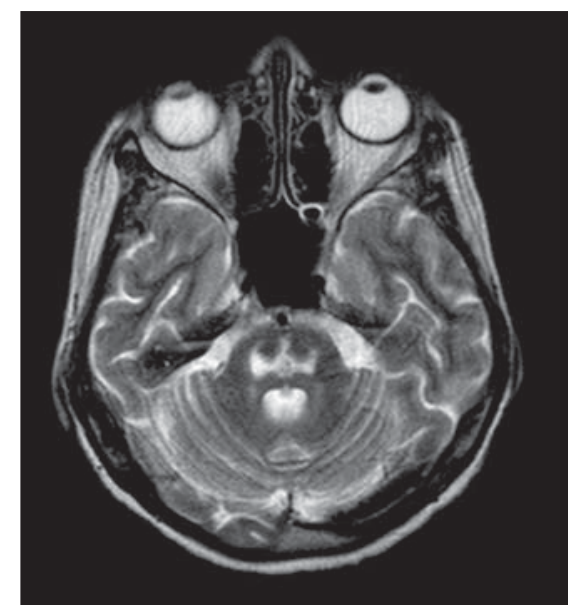

Figura 3. Ressonância magnética, corte axial: imagem da lesão pontina.

3. Sugimoto T, Murata T, Omori M, et al. Central pontine myelinolysis associated with hypokalaemia in anorexia nervosa. J Neurol Neurosurg Psychiatry. 2003;74:353-5.

4. Martin RJ. Central pontine and extrapontine myelinolysis: the osmotic demyelination syndromes J Neurol Neurosurg Psychiatry. 2004;75 Suppl 3:iii22-8.

5. Thompson PD, Miller D, Gledhill RF, et al. Magnetic resonance imaging in central pontine myelinolysis. J Neurol Neurosurg Psychiatry. 1989;52: 675-7.

6. Germiniani FMB, Roriz M, Nabhan SK, et al. Mielinólise pontina central e extra-pontina em paciente alcoolista sem distúrbios hidro-eletrolíticos: relato de caso. Arq Neuropsiquiatr. 2002;60: 1030-3.

7. Abbott R, Silber E, Felber J, et al. Osmotic demyelination syndrome. BMJ. 2005;331:829-30.

8. Howard SA, Barletta JA, Klufas RA, et al. Best cases from the AFIP: Osmotic demyelination syndrome. Radiographics. 2009;29:933-8. 